\title{
Analysis of costs for pandemic management in a tertiary-care hospital in Italy: An investment for a more resilient structure
}

\author{
Angelo Baggiani MD ${ }^{1,2}$, Silvia Briani MD¹, Grazia Luchini MD¹, Mauro Giraldi MD¹, Jacopo Fernandez MD¹, Carla Collecchi

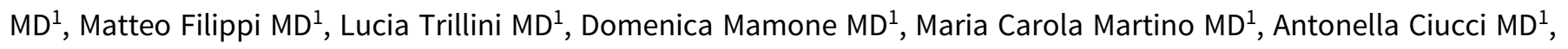 \\ Michele Cristofano $\mathrm{MD}^{1}$, Antonella De Vito $\mathrm{MD}^{1}$, Gabriella Pellegrini MD${ }^{1}$, Grazia Valori $\mathrm{MD}^{1}$, Guglielmo Arzilli $\mathrm{BS}^{2}$, \\ Daniele Sironi BS², Tommaso Mariotti BS², Francesca Papini BS², Virginia Casigliani BS², Giuditta Scardina $\mathrm{BS}^{2}$, \\ Giacomo Visi $\mathrm{BS}^{2}$, Beatrice Casini MD ${ }^{1,2}$, Andrea Porretta MD ${ }^{1,2}$, Michele Totaro BS ${ }^{2}$, Gaetano Privitera $\mathrm{MD}^{1,2}$ and \\ Carlo Milli MD ${ }^{1}$ \\ ${ }^{1}$ The Azienda Ospedaliero Universitaria Pisana, Pisa, Italy and ${ }^{2}$ Department of Translational Research and the New Technologies in Medicine and Surgery, \\ University of Pisa, Pisa, Italy
}

To the Editor - The tertiary-care teaching hospital of Pisa (Azienda Ospedaliera Universitaria Pisana, AOUP) received its first coronavirus disease 2019 (COVID-19) patient on March 4. During the outbreak, this hospital setting underwent major reorganization to respond to the situation. Hospital wards and patient management protocols were modified to quickly adapt to the clinical needs of the patients as well as to ensure patient safety and healthcare worker (HCW) protection from infection. ${ }^{1,2}$

The execution of this strategy to deal with the epidemic imposed significant costs on our hospital. Currently, many expenditure models have been published, as data concerning national health insurance and losses in terms of investments in the various economic sectors. ${ }^{3-5}$

We quantified economic costs incurred by the AOUP from March to July 2020 for the management of the COVID-19 pandemic, focusing on the structural costs for the implementation of the present structure and for the realization of a new COVID-19 hospital.

AOUP is organized into 2 main facilities for a total of 1,082 beds. For pandemic management, the Cisanello facility was reorganized and 160 bed places were dedicated to COVID-19 patients in medical wards, 39 beds in intensive care units, and 24 bed for C-PAP therapy. ${ }^{1}$ Santa Chiara facility is an old pavilion hospital that has been gradually disused. A building that used to accommodate the old emergency room has been renovated as the city's COVID-19 center.

For the purpose of this analysis, we considered 3 phases: phase 1 (March 4-May 4); phase 2 (May 4-July 4), and phase 3 (March 15-July 4).

In the first phase, the emergency was addressed by increasing response to COVID-19 patients. Ordinary wards were progressively closed to dedicate these areas to COVID-19 patients. Therapeutic pathways were reorganized, and COVID-19 cases were stratified into patients requiring low-, medium-, and highintensity care. Construction of negative pressure chambers in

Author for correspondence: Prof Angelo Baggiani, E-mail: angelo.baggiani@med. unipi.it

Cite this article: Baggiani A, et al. (2021). Analysis of costs for pandemic management in a tertiary-care hospital in Italy: An investment for a more resilient structure. Infection Control \& Hospital Epidemiology, 42: 1410-1412, https://doi.org/10.1017/ice.2020.1311 operating theatres and the extension of intensive care wards were carried out.

In the second phase, the objectives were the radical sanitization of the areas dedicated to COVID-19 patients, the reconversion to their original use, and the gradual resumption of outpatient activities by eliminating the waiting lists created and of visits to patients.

The objective of the third phase was to create a hospital for COVID-19 patients in the Santa Chiara facility to prepare for future outbreaks.

For each phase, we analyzed costs directly related to the preparedness and the management of the epidemic (Table 1).

In phase 1 , the final cost accrued was $€ 342,444.91$ (US $\$ 399,952.17)$ for the technical area. Furthermore, $€ 70,000.00$ (US $\$ 81,755.20$ ) was attributed to the adaptation of the ventilation system of the wards from positive pressure to negative pressure. For the costs sustained by the health management unit (HMU), we estimated the total expenditure to be $€ 2,479,421.79$ (US $\$ 2,895,794.65$ ). In total, $€ 1,586,505.57$ (US\$1,852,929.72) was attributed to medical devices. For pharmaceuticals, $€ 680,000.00$ (US\$794,119.19) was spent, and $€ 40,000.00$ (US\$46,712.89) was spent to purchase hydroalcoholic gel for the entire hospital. Screening of patients and HCWs for severe acute respiratory coronavirus virus 2 (SARS-CoV-2) cost $€ 1,466,666.67$ (US $\$ 1,712,806.10)$. In addition, $€ 585,136.49$ (US\$683,346.90) was spent to recruit healthcare workers, and $€ 10,000.00$ (US\$11,678.42) was spent in accommodation services for employees.

In phase 2, $€ 740,000.00$ (US\$864,202.99) was spent on the technical area for cleaning and reconversion of the aeraulic facilities. In addition, $€ 560,000.00$ (US\$653,991.45) was spent by the HMU for cleaning and sanitizing COVID-19 wards. Costs related to environmental monitoring and microbiological analyses performed before the reopening of the departments and restart of ordinary activities amounted to $€ 13,672.00$ (US\$15,972.23).

In phase $3, € 3,817,882.00$ (US\$4,460,216.00) was spent for the construction of the new COVID-19 patients hospital. Most of this expense was for structural costs and health furnishings. In addition, $€ 6,882.00$ (US\$8,039.85) was spent for environmental microbiological analyses.

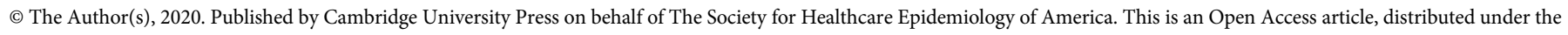

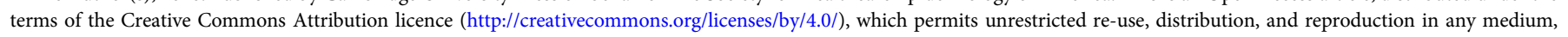
provided the original work is properly cited. 
Table 1. Costs Directly Related to the Preparedness and the Management of the COVID-19 Epidemic in Azienda Ospedaliera Universitaria Pisana

\begin{tabular}{|c|c|c|c|}
\hline \multirow[b]{2}{*}{ Phase } & \multirow[b]{2}{*}{ Description } & \multicolumn{2}{|c|}{ Costs } \\
\hline & & Euros & US\$ \\
\hline \multirow{16}{*}{ Phase 1} & Technical area (COVID hospital rearrangement) & $338,444.51$ & $395,239.17$ \\
\hline & Technical area (site safety charges) & $4,000.00$ & $4,671.24$ \\
\hline & Ventilation system adaption (from positive to negative pressure) & $70,000.00$ & $81,755.40$ \\
\hline & Health management units (cleaning setting improvement) & $154,648.22$ & $180,618.96$ \\
\hline & Health management units (biological materials transport) & $20,000.00$ & $23,358.69$ \\
\hline & Health management units (security services) & $65,268.00$ & $76,228.74$ \\
\hline & Health management units (special waste disposal) & $20,000.00$ & $23,358.69$ \\
\hline & Medical devices (including FFP2/FFP3 masks) & $1,586,505.57$ & $1,852,829.24$ \\
\hline & Health furnishing & $633,000.00$ & $739,260.50$ \\
\hline & Pharmaceutical spending for COVID patients) & $446,666.67$ & $521,647.75$ \\
\hline & Pharmaceutical spending for medical gases & $233,333.33$ & $272,502.55$ \\
\hline & Hydroalcoholic gel & $40,000.00$ & $46,714.72$ \\
\hline & SARS COV-2 screening test & $1,466,666.67$ & $1,712,824.47$ \\
\hline & Administrative burden expense (notebook) & $20,000.00$ & $23,358.69$ \\
\hline & New healthcare workers recruitment & $585,136.49$ & $683,342.79$ \\
\hline & Accommodation services for employees & $10,000.00$ & $11,678.35$ \\
\hline \multirow[t]{3}{*}{ Phase 2} & Technical areas (aeraulic facilities reconversion and cleaning) & $740,000.00$ & $864,197.80$ \\
\hline & Health Management Units (wards cleaning and sanitizing) & $560,000.00$ & $653,984.76$ \\
\hline & Environmental monitoring and microbiological analysis & $13,672.00$ & $15,966.57$ \\
\hline \multirow[t]{2}{*}{ Phase 3} & New COVID hospital reconstruction (structural costs and health furnishing) & $3,817,882.00$ & $4,458,636.85$ \\
\hline & Environmental monitoring and microbiological analysis & $6,882.00$ & $8,037.01$ \\
\hline
\end{tabular}

In total, $€ 13,556,355.43$ (US $\$ 15,837,124.73$ ) was spent globally for the 3 phases: $€ 8,417,919.43$ (US\$9,837,164.61) was spent in phase $1, € 1,313,672.00$ (US\$1,535,154.60) was spent in phase 2 , and $€ 3,824,764.00$ (US\$4,469,611.93) was spent in phase 3 .

Healthcare facilities had to quickly adapt; they underwent huge changes to protect HCWs, to manage COVID-19 patients, and to limit the risk of infection for other inpatients. The way health services are delivered has been greatly modified at our institution during the pandemic. ${ }^{6}$

Meeting these challenges has entailed significant expenditure in economic terms. Even if many reports on the costs that health systems had to face because of the COVID-19 emergency have already been published, it is difficult to quantify the real expenditure, and the estimates are most likely underrepresented. In Italy, according to the ALTEMS report, ${ }^{7}$ the total impact on hospital expenditures has been $€ 1,586,858,655$ (US $\$ 1,854,400,002$ ).

In our study, the entire process of conversion (the reconversion of Cisanello and requalification of Santa Chiara) cost a total of $€ 13,556,355.43$ (US $\$ 15,840,470.55$ ). These resources were deployed by making decisions toward significant benefits. Furthermore, we set up adequate infrastructures to meet possible future waves.

The placement of these funds is in accordance with the WHO guidelines, which affirm that expenditures for COVID-19 should lead to longer-term, wider benefits in line with national needs for sustainable capacities. ${ }^{8}$ Our hospital has made efforts and incurred costs to adapt in a short time to the emerging crisis. We used this opportunity to increase the hospital's resilience and preparedness.
The strategies adopted, with the related costs, have allowed us not only to overcome the acute phase but also to prepare the necessary resources for future crises.

Acknowledgments. We acknowledge the efforts of healthcare workers and essential workers during the COVID-19 pandemic.

Financial support. No financial support was provided relevant to this article.

Conflicts of interest. All authors report no conflicts of interest relevant to this article.

\section{References}

1. Baggiani A, Briani S, Luchini G, et al. Management of healthcare areas for the prevention of COVID-19 emergency in an Italian teaching hospital (Pisa, Tuscany): a hospital renovation plan. Infect Control Hosp Epidemiol 2020;41:1368-1369.

2. Baggiani A, Briani S, Luchini G, et al. Preparedness and response to the COVID-19 emergency: experience from the teaching hospital of Pisa, Italy. Int J Environ Res Public Health 2020;17. doi: 10.3390/ ijerph17207376.

3. Nicola M, Alsafi Z, Sohrabi C, et al. The socio-economic implications of the coronavirus pandemic (COVID-19): a review. Int J Surg 2020;78: 185-193.

4. Bartsch SM, Ferguson MC, McKinnell JA, et al. The Potential Health Care Costs And Resource Use Associated With COVID-19 In The United States. Health Aff (Millwood) 2020;39:927-935.

5. Coronini-Cronberg S, John Maile E, Majeed AA-O. Health inequalities: the hidden cost of COVID-19 in NHS hospital trusts? J R Soc Med 2020;115: 179-184. 
6. Strengthening health systems resilience: key concepts and strategies. European Observatory on Health Systems and Policies website. https://www.euro.who.int/en/about-us/partners/observatory/publications/ policy-briefs-and-summaries/strengthening-health-systems-resilience-keyconcepts-and-strategies-2020. Published 2020. Accessed October 29, 2020.
7. Postgraduate School of Health Economics and Management. Analisi dei modelli organizzativi di risposta al COVID-19: Instant REPORT 15. Rome; 2020.

8. World Health Organization. Investing In and Building Longer-Term Health Emergency Preparedness During the COVID-19 Pandemic. Geneva: WHO; 2020.

\title{
Is it wise not to include hair and shoe covers in personal protective equipment (PPE) recommendations?
}

\author{
Chenyu Sun MD,MSC ${ }^{1}$ (1), Mubashir Ayaz Ahmed MD ${ }^{1}$ and Ce Cheng DO 2 \\ ${ }^{1}$ AMITA Health Saint Joseph Hospital Chicago, Chicago, Illinois and ${ }^{2}$ The University of Arizona College of Medicine at South Campus, Tucson Arizona
}

To the Editor-Coronavirus disease 2019 (COVID-19), caused by severe acute respiratory syndrome coronavirus 2 (SARS-CoV-2), has been spreading globally for more than half year. ${ }^{1}$ Healthcare workers (HCWs) on COVID-19 floors and units are aware of the higher risk of contracting SARS-CoV-2." "Routine care can be resumed only with sufficient and adequate personal protective equipment (PPE)" to protect HCWs to ensure continuous patient care during this pandemic. ${ }^{2}$ In China, $4 \%$ of confirmed cases in the first month of COVID-19 outbreak occurred among HCWs, with even higher rates in Europe due to delayed recognition of COVID-19 rather than PPE failures. ${ }^{3}$ However, the items included in PPE protocol and policies vary from institution to institution. The US Centers for Disease Control and Prevention (CDC) does not include hair covers and shoe covers in their PPE recommendations for HCWs. ${ }^{4}$

Despite the CDC not including them, hair covers and shoe covers, along with face masks, gowns, gloves, and other PPE are often used to prevent contamination from patient contact and droplets. ${ }^{1}$ A recent study suggested that the shoes of HCW might serve as a vector of SARS-CoV-2, transferring it from floors in COVID-19 rooms to floors throughout the unit. ${ }^{5}$ This is not surprising because SARS-CoV-2 contamination was common on floors in COVID-19 patient rooms. ${ }^{5,6}$ Although data on how long SARS-CoV-2 can survive on hairs, or whether it is common to have the contamination on hairs of HCWs are very limited, the virus remains viable for hours to days on different materials. ${ }^{7}$ Therefore, the potential contamination on hairs of HCWs may represent risks of nosocomial infection among non-COVID-19 patients.
We believe it is better to be cautious rather than regretful, and HCWs should be provided shoe covers and hair covers as part of PPE when providing care for COVID-19 patients. More studies will also be needed to assess the risk of contamination on human hairs as well as the efficacy of hair and shoe covers in healthcare settings.

\section{References}

1. Guddati A. Protection of healthcare professionals during an epidemic: medical, ethical, and legal ramifications. Interact J Med Res 2020;9:e19144.

2. Bresler AM, Bischoff MS, Böckler D. SARS-CoV-2-how can and must medical personnel protect themselves? Gefasschirurgie 2020;15:1-10.

3. Rhee C, Baker MA, Klompas M. The COVID-19 infection control arms race. Infect Control Hosp Epidemiol 2020. doi: 10.1017/ice.2020.211.

4. Interim infection prevention and control recommendations for healthcare personnel during the coronavirus disease 2019 (COVID-19) pandemic. Centers for Disease Control and Prevention website. https://www.cdc.gov/ coronavirus/2019-ncov/hcp/infection-control-recommendations.html. Updated July 15, 2020. Accessed September 22, 2022.

5. Redmond SN, Dousa KM, Jones LD, et al. Severe acute respiratory syndrome coronavirus 2 (SARS-CoV-2) nucleic acid contamination of surfaces on a coronavirus disease 2019 ward and intensive care unit. Infect Control Hosp Epidemiol 2020. doi: 10.1017/ice.2020.416.

6. Kim UJ, Lee SY, Lee JY, et al. Air and environmental contamination caused by COVID-19 patients: a multi-center study. J Korean Med Sci 2020; 35:e332.

7. van Doremalen N, Bushmaker T, Morris DH, et al. Aerosol and surface stability of SARS-CoV-2 as compared with SARS-CoV-1. $N$ Engl J Med 2020;382:1564-1567.

\footnotetext{
Author for correspondence: Chenyu Sun, E-mail: drsunchenyu@yeah.net

Cite this article: Sun C, Ayaz Ahmed M, and Cheng C. (2021). Is it wise not to include hair and shoe covers in personal protective equipment (PPE) recommendations?. Infection Control \& Hospital Epidemiology, 42: 1412, https://doi.org/10.1017/ice.2020.1306
}

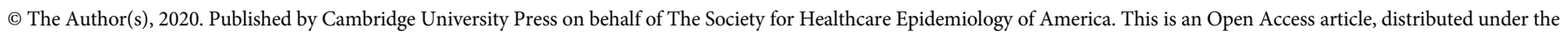
terms of the Creative Commons Attribution licence (http://creativecommons.org/licenses/by/4.0/), which permits unrestricted re-use, distribution, and reproduction in any medium, provided the original work is properly cited. 